\title{
Patient Participation and the Environment: A Scoping Review of Instruments
}

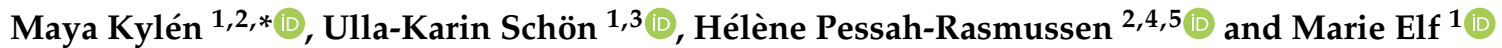 \\ 1 School of Health and Welfare, Dalarna University, 79188 Falun, Sweden; \\ ullakarin.schon@socarb.su.se (U.-K.S.); mel@du.se (M.E.) \\ 2 Department of Health Sciences, Lund University, 22100 Lund, Sweden; helene.pessah@skane.se \\ 3 Department of Social Work, Stockholm University, 10691 Stockholm, Sweden \\ 4 Department of Neurology, Rehabilitation Medicine, Memory Disorders and Geriatrics, Skåne University \\ Hospital, 22185 Lund, Sweden \\ 5 Department of Clinical Sciences, Lund University, 22184 Lund, Sweden \\ * Correspondence: maya.kylen@med.lu.se
}

check for updates

Citation: Kylén, M.; Schön, U.-K.; Pessah-Rasmussen, H.; Elf, M. Patient Participation and the Environment: A Scoping Review of Instruments. Int. J. Environ. Res. Public Health 2022, 19, 2003. https://doi.org/10.3390/ ijerph19042003

Academic Editor: Stefan Nilsson

Received: 16 December 2021

Accepted: 5 February 2022

Published: 11 February 2022

Publisher's Note: MDPI stays neutral with regard to jurisdictional claims in published maps and institutional affiliations.

Copyright: (c) 2022 by the authors. Licensee MDPI, Basel, Switzerland. This article is an open access article distributed under the terms and conditions of the Creative Commons Attribution (CC BY) license (https:// creativecommons.org/licenses/by/ $4.0 /)$.

\begin{abstract}
Patient participation and the environment are critical factors in achieving qualitative healthcare. We conducted a systematic scoping review using Arksey and O'Malley's framework to identify instruments intended to measure patient participation. We assessed those instruments' characteristics, which areas of the healthcare continuum they target, and whether environmental factors are considered. Instruments were considered eligible if they represented the patient perspective and measured patient participation in healthcare. The search was limited to articles written in English and published in the last 10 years. We extracted concepts (i.e., patient empowerment, patient participation, and patient-centeredness) based on the framework developed by Castro et al. and outcomes of significance regarding the review questions and specific objectives. The search was conducted in PsycINFO, CINHAL/EBSCO, and PubMed in September 2019 and July 2020. Of 4802 potential titles, 67 studies reported on a total of 45 instruments that met the inclusion criteria for this review. The concept of patient participation was represented most often in these studies. Although some considered the social environment, no instrument was found to incorporate and address the physical environment. Thirteen instruments were generic and the remaining instruments were intended for specific diagnoses or healthcare contexts. Our work is the first to study instruments from this perspective, and we conclude that there is a lack of instruments that measure aspects of the social and physical environment coherently as part of patient participation.
\end{abstract}

Keywords: patient participation; healthcare; environment; scoping review; patient-reported instruments

\section{Introduction}

Patient participation is a key component of person-centered care and the quality of health and social care [1-3]. In person-centered care, a service must provide patients with greater decision-making power and more choices and integrate the environment and patients' unique physical, psychosocial, cultural, and emotional needs [4]. Patient participation is associated with better healthcare processes and patient health outcomes, reduced mortality, and lower healthcare costs [5-7]. Patient participation has also been shown to improve motivation, treatment commitment, and self-management among persons living with chronic conditions [8-10]. Current healthcare services use a range of strategies to evaluate the participation of patients and their significant others which are important for the purpose of continuous improvements [11]. For example, the questionnaire Quality from the Patient's Perspective [12] has been used to measure the quality of care by asking questions about patients' participation experiences in surgical units [13]. However, despite its growing significance, patient participation has been poorly implemented in practice and the concept has been vaguely defined [14]. 
Alongside patient participation, the environment is a key factor in attaining quality healthcare and supporting patient health outcomes [15]. Environmental factors are placed at the center in many rehabilitation and disability health models [15-17]. However, little is known about how to integrate environmental factors in the quest to improve care quality and patient health outcomes $[18,19]$. As disability is created when a person with an injury or health condition interacts with an environment that is not supportive [20], this lack of knowledge is a concern. For persons with disabilities, environmental factors have a major impact on everyday participation at the immediate, community, and societal levels [21]. This can be exemplified by the many patients who are discharged from the hospital to homes that are not supportive of their new health situation which may result in activity and participation restrictions as well as being unsafe [22]. Thus, the current trend of short hospital stays for persons with complex health conditions and continued rehabilitation and care in the home $[23,24]$ calls for greater inclusion of the environment in health-related communication across the continuum of care.

The environment comprises a multitude of factors that can either be a barrier to or support patients' participation, functioning, and right to preserve their personal integrity $[15,17]$. For example, in the International Classification of Functioning, Disability, and Health (ICF), environmental factors are defined as those that "make up the physical, social and attitudinal environment in which people live and conduct their lives" [16]. Physical features include the built environment (e.g., stairs or doors), natural environment (e.g., outdoor surfaces), and objects, whereas the social environment can be defined to include the persons with whom one interacts, supports, and has relationships [16]. The impact the environment may have on an individual's life and their possibilities to function depend on the degree of support (e.g., practical, emotional) or demand (e.g., accessibility, usability) that the physical and social environment may have [17]. For example, personenvironment fit theories describe that the adequacy of the fit between a person's functional abilities and environment can affect the person's level of independence, participation, and overall health and well-being [25]. If the fit is good, the person's functioning may be facilitated, and if incompatible, the person may experience maladaptation [26]. Acknowledged also by the World Health Organization (WHO), the ICF states that environmental factors and participation are both crucial for patient health outcomes [16]. Hence, healthcare professionals must integrate environmental factors into their assessments, goal setting, and evaluations to promote patient participation.

When a patient is informed rather than involved, there is a risk that important information about the patient's environmental prerequisites will be lost [27]. For example, inadequate practices of discharge from the hospital-that is, discharge that does not include a dialogue with the patient about his or her home environment and needs post-discharge-may have adverse effects such as dependency in daily activities and social isolation [22]. In addition, the main goal of persons living with complex health conditions is to be part of society. Despite this, much of today's healthcare concentrates on helping patients restore their functional capacity and improve their independence in daily life, while goals involving a person's activities in the environment outside the home are seldomly addressed [28-31].

The concept of patient participation has been poorly defined, and various synonymous terms, such as patient involvement, empowerment, patient-centeredness, and personcentered care, have been used interchangeably in the literature [14]. However, the increasing emphasis on participation by the WHO, governments, patient organizations, and health and social care policies makes it important that we understand the concept of how to measure patient participation and what enables it across the continuum of care.

From an environmental perspective, two things are important for patient participation. First, clinical routines and attitudes need to enable patients to influence and engage in care decisions. Secondly, care interventions should be adapted to the patient's personal preferences and allow patients to participate in everyday life in society [32,33]. We use the framework of Castro and colleagues who define patient participation as revolving 
around a patient's rights and opportunities to influence and engage in decision making about his or her care through a dialogue attuned to her or his preferences, potential, and a combination of her or his experiential and professional expert knowledge [32]. Hence, patient participation addresses the relationship between patients and clinicians within healthcare systems, but it is also a practice with a common goal to include the patient in the healthcare system [14]. Castro argued that patient participation can be seen as an approach to achieve person-centered care and promote patient empowerment [32]. Thus, patient participation includes three essential related concepts: patient empowerment, patient participation, and patient-centeredness. Although several related systematic reviews have been published, patient participation is an evolving concept demanding repetitive reevaluations [5,34-36], especially regarding the role of the environment.

In summary, patient participation is high on the political agenda and considered important within the scientific community, but the concept remains unexplored, especially in regard to the role played by the environment. To guide researchers and, in particular, healthcare professionals in their choice of an appropriate instrument for patient participation and to optimize existing instruments, knowledge of how environmental factors are represented is needed. In this work, we included self-reported instruments (i.e., the respondents read the question and give their responses by themselves without interference) to measure patient participation for specific health conditions and care contexts. This strategy made it possible to identify the instruments that cover environmental aspects and the generic instruments that can be used in different contexts which we argue is essential for empowering patients in person-centered care. The objective of this review was to describe the available instruments for measuring patient participation, evaluate each instrument for the presence of environmental factors, and investigate the area of the healthcare continuum at which they are targeted.

\section{Materials and Methods}

A scoping review methodology based on the framework of Arksey and O'Malley and recommendations by Levac et al. was used to synthesize the research and map the nature, volume, and characteristics of research within a field of interest $[37,38]$. The preferred reporting items for systematic reviews and meta-analyses extension for scoping reviews (PRISMA-ScR) checklist was used to ensure that all relevant aspects of scoping reviews were included [39]. The following research questions were developed.

- What are the available instruments used for measuring the aspects of patient participation in healthcare?

- What aspects of patient participation do these instruments address?

- Which areas of the healthcare continuum do these instruments target?

- Which environmental aspects do these available instruments include?

The systematic process to answer these questions involved the following phases: the identification of the research question, the identification of relevant studies, study selection, the charting of the data, and the collating, summarizing, and reporting of the results.

\subsection{Identifying Studies}

The initial search was conducted on 2 September 2019, in PsycINFO (psychological, social, behavioral, and health sciences), CINHAL/EBSCO (nursing and allied health), and PubMed (biomedical). The following keywords were used: patient participation, patient involvement, professional-patient relations, client-centered participation, patient empowerment, patient-centered care, patient centeredness, and shared decision making. The following search terms were also used: scale, instrument, and measurement. The search query was tailored to the specific requirements of each database (Supplementary). Qualitative studies were excluded, as were those that were not published in the last 10 years.

A snowball technique was adopted in which citations within articles were handsearched to identify the original source of instruments. A follow-up search of the three 
electronic databases was conducted on 12 June 2020, to identify any additional instruments published after the initial search (Supplementary).

\subsection{Citation Management}

All references $(n=4802)$ were imported into the bibliographic manager EndNote X9 [40]. All duplicates were removed first automatically and then by hand $(n=1038)$. Title and abstract relevance screening and the data characterization of full-text articles were conducted in EndNote X9.

\subsection{Eligibility Criteria}

Figure 1 provides a flowchart illustrating the process for screening and assessing the studies identified in the search. After eliminating all duplicates, titles and abstracts were screened for relevance. Studies were eligible for inclusion if they reported on the development and/or validation of questionnaire-based self-reported measurements. The instruments had to represent the patient perspective and measure patient participation in healthcare. Instruments that were not fully developed or validated and studies that included respondents other than patients were excluded.

Articles that did not focus on any of the three essential concepts, patient empowerment, patient participation, and patient-centeredness as defined by Castro [32], were excluded. Additionally, articles that investigated the relationships among variables and used patient participation as an outcome were excluded, but their reference lists were reviewed to identify the original instruments used. When the same instrument was reported in more than one publication (e.g., in a journal article and an electronic report or in a work that has been translated to a different language), only the article reporting the original instrument or modified version was included.

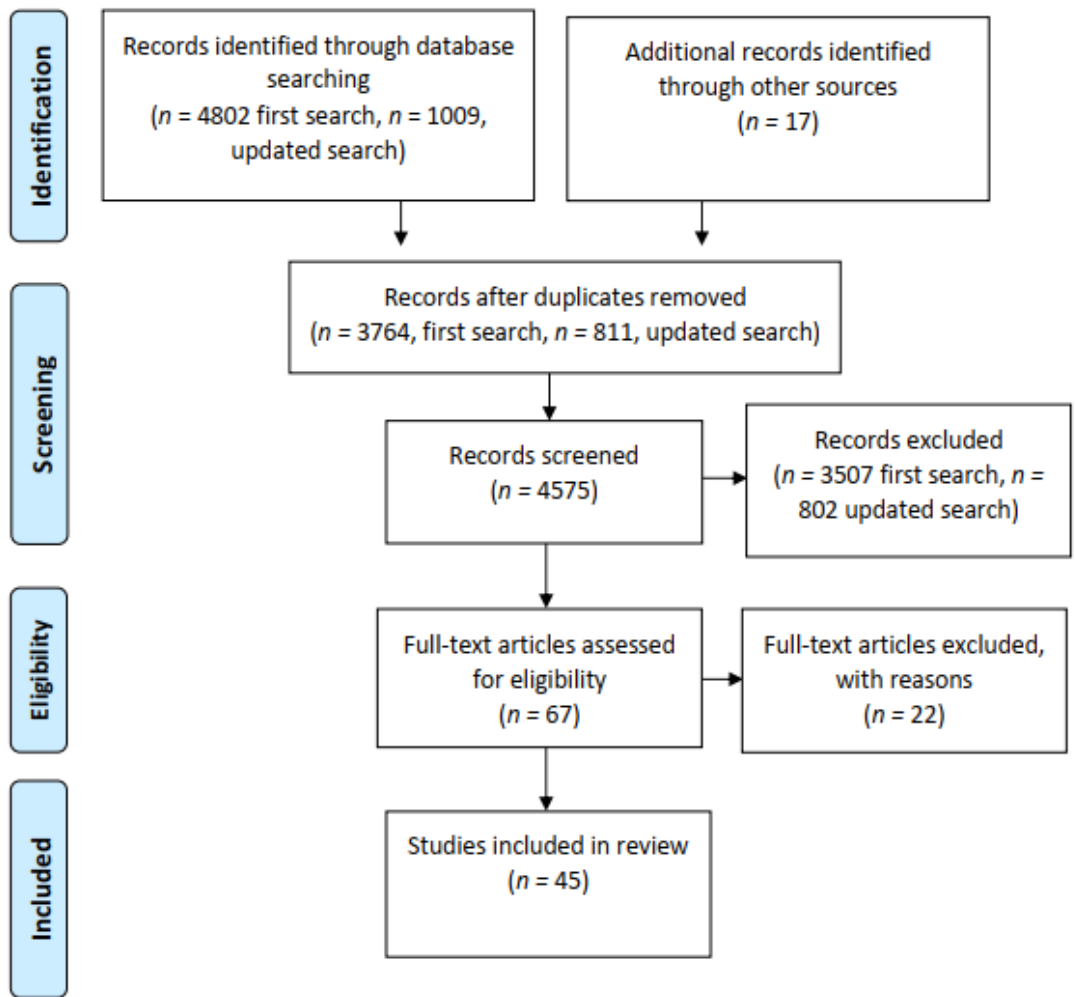

Figure 1. PRISMA chart.

\subsection{Title and Abstract Relevance Screening}

For the first level of screening, only titles and abstracts were reviewed to identify articles that met the inclusion criteria (see Table 1). The title and abstract of each article were 
independently screened by two reviewers. Titles for which an abstract was not available were included in the subsequent review of full-text articles in the data characterization phase. Reviewers met throughout the screening process to discuss any uncertainties related to study selection [38].

Table 1. Overview of inclusion criteria.

\begin{tabular}{|c|}
\hline Inclusion \\
\hline Peer-reviewed journal articles \\
\hline Published between 2009 and 2020 \\
\hline Participants: adults who are aged 18 years or over \\
\hline $\begin{array}{l}\text { The review considered any self-reported instruments that intended to measure patient } \\
\text { participation in healthcare }\end{array}$ \\
\hline Exclusion \\
\hline Qualitative studies \\
\hline Systematic reviews \\
\hline Studies involving participants less than 18 years of age \\
\hline Studies published in languages other than English \\
\hline Not original research or research using a single item survey question \\
\hline No instrument was available to in the article or attached as an appendix \\
\hline The measure was designed to be completed by someone other than the patient \\
\hline The paper described application of the measure but not its development \\
\hline
\end{tabular}

\subsection{Charting the Data}

After title and abstract screening, full-text articles were uploaded to Rayyan, a webbased tool for systematic reviews [41]. If full-text articles were not available, then the authors contacted the respective corresponding author. Each author independently reviewed and labelled all articles and met to resolve any conflicts, ensuring consistency between reviewers and in terms of the research question and purpose [38]. Studies that did not meet the eligibility criteria were excluded.

An Excel file was created and used to extract specific details such as publication year, instrument name, population, terminology, and concepts used to describe patient participation and significant outcomes regarding the review question and specific objectives. Instruments were labeled either as (1) generic, i.e., instruments that could be used for different populations and contexts, or (2) specific, i.e., instruments that could be tested and used in a specific care context (e.g., inpatient care) or for a specific diagnosis (e.g., cancer).

\subsection{Summarizing and Reporting the Results}

The data were coded and validated in Rayyan [41]. At this stage, attention was paid to the domains assessed, the number of items, the theoretical underpinnings, and the presence of environmental factors. The concepts described in the articles based on theories or attributes were reflected in the conceptual framework developed by Castro et al. [32]. However, there remains no consensus on the use and meaning of these concepts, which is why attempts to thematize the relevant studies have been considered valuable.

\section{Results}

The original and updated searches yielded 4802 and 1009 potentially relevant articles, respectively. After deduplication ( $n=3764$ in the first search and 811 in the updated search) and relevance screening, 50 articles met the inclusion criteria based on titles and abstracts, and the corresponding full-text articles were thus reviewed. In addition, 17 articles containing scales were found through citation checks of articles that used scales as outcome 
measures. Hence, 67 articles were read at this stage. Of these, 22 articles were excluded for various reasons (e.g., survey rather than validated instrument, instruments measuring concepts other than patient participation such as how patients cope with poor health). In total, 45 citations were included in the study (Figure 1).

An overview of the 45 instruments and their abbreviations included in this review is presented in Table 2 .

\subsection{Concepts}

Based on the definitions of patient participation and its related concepts by Castro and colleagues, the concept of patient participation was represented most often in the included studies $(n=24)$, followed by patient centeredness $(n=12)$ and patient empowerment $(n=9)$ [32]. In terms of the patient-centeredness instruments, aspects such as the patients' perceptions of informative, respectful, and attentive staff in the HSOPE [48] care coordination; continuity and shared responsibility in PPIC [80]; and physical comfort and emotional support in QPCC [86] were also measured.

Patient empowerment instruments contained intrapersonal and behavioral empowerment aspects, such as positive communication between patients and caregivers [47], illness and stress management [72], and encouragement to take control of one's own health [78], as well as empowerment facilitators such as social support, access to staff, and information in PPPNBS [81].

Many of the patient participation instruments were intended to measure patients' rights and opportunities to engage in planning and decision making about their care. CollaboRATE [43], iSHARE [52], a decision-making instrument used in surgical treatment [58], PPRQ [59], SDM-Q-9 [70], CAHPS [71], PPPIP [79], and 4Ps [82], all focused on sharing knowledge and patient participation in clinical care contexts. While PCPS [53] focused primarily on the patient communication pattern, other patient participation instruments, such as SURE [69], PPIQ [83], and PrepDM [85], focused on decisional conflict and patient readiness to make a decision. In addition, the evaluation of communication [44], decision regret [45], decision-making effectiveness [54] and the decisional balance of a patient's choice in terms of substance abuse treatment was in focus [76].

\subsection{Instruments including Environmental Aspects}

No single instrument, item, or explanatory text was found to incorporate the physical environment. While most instruments had no context-driven items at all, 19 instruments considered the social environment to various extents. Of these instruments, few were theoretically grounded in a model that acknowledges the interplay between a person's health and the environment for the purpose of enhancing patient participation (e.g., see [61]).

The instruments containing the most social environment items were generally categorized as patient-centered and often covered several domains. Aspects such as family and friend involvement were covered in CAHPS [71] and QPCCC [86], the resources available in the neighborhood to support patients in coping with health conditions were covered in IEXPAC [49] and PPIC [80], the extent to which healthcare providers ask about a patient's family life was covered in PPPC-R [61], concerns about how to manage family life were covered in PCCE [63] and QPCCC [86], and adequate information about what to expect in terms of challenges in daily life was covered in the CPEQ [72].

Furthermore, a patient's ability to cope with personal and social concerns and the degree to which she or he, at hospital discharge, was engaged in discussions regarding sexual activity, housework, gardening, and returning to work was considered $[47,65]$. 
Table 2. Overview of instruments

\begin{tabular}{|c|c|c|c|c|c|c|c|}
\hline Name of Instrument & Abbreviation & Country of Origin & Concept $^{\mathrm{a}}$ & Type of Instrument ${ }^{b}$ & Care Context ${ }^{c}$ & $\begin{array}{l}\text { Environmental } \\
\text { Factors }\end{array}$ & Reference \\
\hline $\begin{array}{l}\text { Clinical Decision-making Involvement } \\
\text { and Satisfaction }\end{array}$ & CDIS & UK & Patient participation & Specific & Outpatient care & - & [42] \\
\hline CollaboRATE & CollaboRATE & USA & Patient participation & Generic & Generic & - & [43] \\
\hline COMRADE & COMRADE & UK & Patient participation & Generic & Generic & - & [44] \\
\hline Decision Regret Scale & $\mathrm{N} / \mathrm{A}$ & Canada & Patient participation & Generic & Generic & - & [45] \\
\hline Decisional Conflict Scale & DCS & Canada & Patient participation & Generic & Generic & Yes Social & {$[46]$} \\
\hline Diabetes Empowerment Questionnaire & $\mathrm{N} / \mathrm{A}$ & Iran & $\begin{array}{c}\text { Patient } \\
\text { empowerment }\end{array}$ & Specific & N/A Diabetes & Yes Social & [47] \\
\hline $\begin{array}{l}\text { Health Services OutPatient } \\
\text { Experience questionnaire }\end{array}$ & HSOPE & Italy & Patient centeredness & Specific & Outpatient care & - & {$[48]$} \\
\hline $\begin{array}{l}\text { Instrument for Evaluation of the } \\
\text { Experience of Chronic Patients }\end{array}$ & IEXPAC & Spain & Patient centeredness & Specific & Care transition & Yes Social & [49] \\
\hline $\begin{array}{l}\text { Inpatient Involvement in Medication } \\
\text { Safety Scale }\end{array}$ & IIMSS & China & $\begin{array}{c}\text { Patient } \\
\text { empowerment }\end{array}$ & Specific & Inpatient care & - & {$[50]$} \\
\hline $\begin{array}{l}\text { Instrument measuring empowerment } \\
\text { needs of patients after a percutaneous } \\
\text { coronary intervention }\end{array}$ & $\mathrm{N} / \mathrm{A}$ & China & $\begin{array}{c}\text { Patient } \\
\text { empowerment }\end{array}$ & Specific & Inpatient care & Yes Social & [51] \\
\hline $\begin{array}{l}\text { Patient empowerment in } \\
\text { long-term conditions }\end{array}$ & $\mathrm{N} / \mathrm{A}$ & UK & $\begin{array}{c}\text { Patient } \\
\text { empowerment }\end{array}$ & Specific & Outpatient care & Yes Social & [54] \\
\hline $\begin{array}{l}\text { Patient Empowerment } \\
\text { Strategies Questionnaire }\end{array}$ & PES-Q & Greece & $\begin{array}{c}\text { Patient } \\
\text { empowerment }\end{array}$ & Specific & Inpatient care & Yes Social & [55] \\
\hline Patient Engagement Index & PEI & China & Patient participation & Generic & Generic & - & [56] \\
\hline Patient Motivation Questionnaire & $\mathrm{N} / \mathrm{A}$ & Egypt & $\begin{array}{c}\text { Patient } \\
\text { empowerment }\end{array}$ & Specific & Inpatient care & - & [57] \\
\hline $\begin{array}{l}\text { Patient participation in decision making } \\
\text { in surgical treatment }\end{array}$ & $\mathrm{N} / \mathrm{A}$ & Norway & Patient participation & Specific & Inpatient care & - & [58] \\
\hline $\begin{array}{l}\text { Patient Participation in } \\
\text { Rehabilitation Questionnaire }\end{array}$ & PPRQ & Sweden & Patient participation & Specific & Outpatient care & Yes Social & [59] \\
\hline Patient Participation Questionnaire & PPQ & Denmark & Patient participation & Specific & Inpatient care & - & [60] \\
\hline $\begin{array}{l}\text { Patient Perception of } \\
\text { Patient-Centeredness Questionnaire }\end{array}$ & PPPC-R & Canada & Patient centeredness & Specific & Outpatient care & Yes Social & [61] \\
\hline
\end{tabular}


Table 2. Cont.

\begin{tabular}{|c|c|c|c|c|c|c|c|}
\hline Name of Instrument & Abbreviation & Country of Origin & Concept $^{a}$ & Type of Instrument ${ }^{b}$ & Care Context ${ }^{c}$ & $\begin{array}{l}\text { Environmental } \\
\text { Factors }\end{array}$ & Reference \\
\hline $\begin{array}{l}\text { Patient-centered coordination by a care } \\
\text { Team questionnaire }\end{array}$ & PCCCT & Canada & Patient centeredness & Specific & Care transition & - & [62] \\
\hline $\begin{array}{l}\text { Patients and the Cancer Care } \\
\text { Experience Survey }\end{array}$ & PCCE & USA & Patient centeredness & Specific & Inpatient care & Yes Social & [63] \\
\hline $\begin{array}{l}\text { Patients' Perceived Involvement in } \\
\text { Care Scale }\end{array}$ & M-PICS & USA & Patient participation & Specific & N/A Chronic pain & - & [64] \\
\hline $\begin{array}{l}\text { Questionnaire for measuring patient } \\
\text { views of involvement in myocardial } \\
\text { infarction care }\end{array}$ & $\mathrm{N} / \mathrm{A}$ & Sweden & Patient centeredness & Specific & Inpatient care & Yes Social & {$[65]$} \\
\hline $\begin{array}{l}\text { Questionnaire for patient participation in } \\
\text { emergency departments }\end{array}$ & PPED & Sweden & Patient participation & Specific & Inpatient care & - & {$[66]$} \\
\hline $\begin{array}{l}\text { Questionnaire to measure older people's } \\
\text { experience of the Transition Care Program }\end{array}$ & $\mathrm{N} / \mathrm{A}$ & Australia & Patient centeredness & Specific & Care transition & Yes Social & [67] \\
\hline Shared decision-making questionnaire & SDM-Q & Germany & Patient participation & Generic & Generic & - & [68] \\
\hline $\begin{array}{l}\text { Sure of myself; Understand information; } \\
\text { Risk-benefit ratio; Encouragement }\end{array}$ & SURE & Canada & Patient participation & Generic & Generic & - & [69] \\
\hline $\begin{array}{l}\text { The 9-item Shared Decision } \\
\text { Making Questionnaire }\end{array}$ & SDM-Q-9 & Germany & Patient participation & Generic & Generic & - & {$[70]$} \\
\hline $\begin{array}{l}\text { The Cancer Patient } \\
\text { Empowerment Questionnaire }\end{array}$ & CPEQ & Denmark & $\begin{array}{c}\text { Patient } \\
\text { empowerment }\end{array}$ & Specific & Inpatient care & Yes Social & [72] \\
\hline The Care Transition Measure & CTM & USA & Patient centeredness & Specific & Care transition & Yes Social & [73] \\
\hline $\begin{array}{l}\text { The Consumer Quality Index (CQ-index) } \\
\text { Continuum of Care }\end{array}$ & CQ-index & The Netherlands & Patient participation & Specific & Care transition & - & [74] \\
\hline The Control Preferences Scale & CPS & Canada & Patient centeredness & Generic & Generic & - & [75] \\
\hline $\begin{array}{l}\text { The Decisional Balance for Patient Choice } \\
\text { in Substance Abuse Treatment }\end{array}$ & $\mathrm{N} / \mathrm{A}$ & USA & Patient participation & Specific & Outpatient care & Yes Social & [76] \\
\hline The Decisional Engagement Scale & DES-10 & USA & Patient participation & Specific & Inpatient care & - & [77] \\
\hline The patient activation measure & PAM & USA & $\begin{array}{c}\text { Patient } \\
\text { empowerment }\end{array}$ & Generic & Generic & - & [78] \\
\hline $\begin{array}{l}\text { The Patient Participation in Pressure } \\
\text { injury Prevention scale }\end{array}$ & PPPIP & Australia & Patient participation & Specific & N/A Pressure injury & - & [79] \\
\hline $\begin{array}{l}\text { The Patient Perceptions of Integrated } \\
\text { Care survey }\end{array}$ & PPIC & USA & Patient centeredness & Specific & Care transition & Yes Social & {$[80]$} \\
\hline
\end{tabular}


Table 2. Cont.

\begin{tabular}{|c|c|c|c|c|c|c|c|}
\hline Name of Instrument & Abbreviation & Country of Origin & Concept $^{a}$ & Type of Instrument ${ }^{b}$ & Care Context ${ }^{c}$ & $\begin{array}{c}\text { Environmental } \\
\text { Factors }\end{array}$ & Reference \\
\hline $\begin{array}{l}\text { The Patient Perceptions of } \\
\text { Patient-Empowering Nurse } \\
\text { Behaviours Scale }\end{array}$ & PPPNBS & USA & $\begin{array}{c}\text { Patient } \\
\text { empowerment }\end{array}$ & Specific & Inpatient care & Yes Social & [81] \\
\hline $\begin{array}{l}\text { The Patient Preferences for Patient } \\
\text { Participation tool }\end{array}$ & The 4Ps & Sweden & Patient participation & Generic & Generic & - & [82] \\
\hline $\begin{array}{l}\text { The Patient-Professional } \\
\text { Interaction Questionnaire }\end{array}$ & PPIQ & Italy & Patient participation & Generic & Generic & - & [83] \\
\hline $\begin{array}{l}\text { The Picker Patient } \\
\text { Experience Questionnaire }\end{array}$ & PPE-15 & UK & Patient centeredness & Specific & Inpatient care & Yes Social & {$[84]$} \\
\hline $\begin{array}{l}\text { The Preparation for Decision } \\
\text { Making scale }\end{array}$ & PrepDM & Canada & Patient participation & Generic & Generic & - & [85] \\
\hline $\begin{array}{l}\text { The Quality of Patient-Centered } \\
\text { Cancer Care }\end{array}$ & QPCCC & Australia & Patient centeredness & Specific & Inpatient care & Yes Social & {$[86]$} \\
\hline
\end{tabular}

a According to Castro et al [32], b,c Generic, i.e., instruments that could be used for different populations and contexts, or specific, i.e., instruments that could be tested and used in a specific care context or for a specific diagnosis. 
Some instruments, such as DCS [46], primarily focused on patient support from others in making a health-related decision or receiving help in identifying people and/or resources to support in IEXPAC [49], PPIC [80], and PPPNBS [81]. Other instruments contained items asking the patient if his or her significant other had been informed and had the opportunity to be involved in PPRQ [59], CAHPS [71], and CTM [73]. In addition, a few instruments containing social environment aspects were designed for healthcare evaluation purposes. For example, Masters and colleagues [67] developed a questionnaire to measure whether specific processes or events occur following the transitions of older adults from the hospital to the home environment. In this instrument, quality entails that care is linked to the goals of patients, caregivers, and families and that these goals should also concern lifestyle, community participation, relationships, and emotional well-being.

\subsection{Generic Instruments}

Thirteen instruments were labeled as generic. Eleven of them measured patient participation $[43-46,56,68-70,82,83,85]$. One measured patient empowerment [78], and one measured patient centeredness [75]. Most of the generic instruments contained few items and focused on shared decision making. For example, CollaboRATE [43], SDM-Q [68], and the shorter version of SDM-Q9 [70] measured the effort of healthcare professionals toward supporting patient participation in care-related decisions.

When looking at the different generic instruments, one can see that they aim at measuring different facets of decision making. SURE [69] and PrepDM [85] measured patients' readiness and perceptions of support to make decisions before the actual encounter between patients and healthcare professionals, while the decisional regret scale measured decisional regret after a care decision was already made [47]. There are also examples of generic instruments targeting decisional conflict before or after a decision has been made [46]. The other generic patient participation instruments included the 4Ps instrument, measuring patient preferences and whether they have been experienced in encounters with healthcare professionals [82]; PPIQ [83], measuring patients' perceptions of communication, interest in their agenda, empathy, and patient involvement in care; and COMRADE [44], measuring risk communication and patients' confidence in decisions. In addition to these generic instruments, PAM [78] measured patient activation in terms of patient knowledge and confidence, and CPS [75] focused on patients' preferred roles in medical decision making.

\subsection{Healthcare Continuum}

\subsubsection{Instruments for Inpatient Care}

Most instruments were intended to be used in inpatient care. Among them were instruments measuring patient participation during hospitalization; for example, the instruments of Arnetz [65] and $\mathrm{He}$ [51] were developed to be used in heart disease settings. These instruments focused on patient experiences involving nurses' information, support, and recommendations. PPQ [60] was developed to measure patient participation in heart and lung disease decisions during inpatient care. IIMSS [50] focused on patients' involvement in their own medical treatment with the aim of increasing patient safety. PPE-15 [84] determined a patient's overall care experiences. PPPNBS [81] measured the process of empowerment in inpatient care. In addition, Heggland's instrument was developed to assess patient participation in surgical wards [58].

The QPCCC instrument [86] was based on the quality standards of the Institute of Medicine (IOM) [1] and was developed for cancer patients. Additionally, PES-Q [55], iSHARE [52], and CPEQ [72] were developed to be used in oncology settings. The authors who created PES-Q and CPEQ stated that these instruments specifically measure patients' empowerment strategies. DES-10 [77] measured patients' engagement in decisions regarding cancer care. The CAHPS [71] measured overall quality of care with the inclusion of items measuring patients' opportunities to participate and their shared decision making. PCCE [63] was a more general instrument that captured care quality broadly but focused 
on decision making and the information provided. PPED [66] was developed to measure participation in an emergency department.

The remaining instruments had more specific areas of use, such as for pressure injury prevention, i.e., PPPIP [79], as well as the prevention of chronic inflammatory arthritis [57], diabetes [47], and chronic pain [64]. These instruments did not specify if they targeted inpatient care; thus, they could also be used in other settings.

\subsubsection{Care Transition between Various Contexts}

Two instruments specifically aimed to measure care transitions, i.e., between the inpatient setting and primary care or the home. For example, Master's instrument [67] was developed to measure older adults' experiences of transitional care and CTM [73] was developed to measure quality-of-care transitions from the patient perspective. Both instruments aimed to capture the experiences of the entire care transition phase and not only the hospital discharge phase. Questions in CTM concerned whether patients felt that they agreed on their care plan and understood their care plan and medication. IEXPAC [49] and PPIC [80] measured persons' experiences of how care managers were able to integrate and coordinate care across professionals, facilities, and support systems and were able to remain constant over time and between visits. The instruments were patient- and family-centered and based on shared responsibility among patients, family members, and caregivers. Other instruments that measured care coordination were PCCCT [62] and CQ-index [74]. PCCCT captured patients' experiences with the involved professionals, the degree of coordination by providers, and the degree of emphasis on patients' problems, goals, and roles. The CQ index measured patients' experiences in terms of collaboration between general practitioners and specialists.

\subsubsection{Outpatient Care}

Other instruments were developed to be used in the outpatient context. PPRQ [59] aimed to measure patient participation in a rehabilitation context, and PPPC-R [61], HSOPE [48], and Small's [54] instruments were developed to assess patient participation in outpatient settings. Other instruments, such as the one by Finnell and Lee [76], aimed to assess patient readiness for shared decision making in a substance abuse context. The CDIS [42] aimed to measure the clinical decision-making involvement and satisfaction of patients in mental healthcare.

\section{Discussion}

This paper reviewed the available instruments aiming to measure patient participation in healthcare with a specific focus on the related concepts and how environmental factors are considered. Given the lack of consensus regarding the definition of patient participation, our study followed Castro and colleagues [32] and attempted to treat the concept broadly and thus included other related concepts. As patient participation is an important quality measure of care and rehabilitation [3], we explored the instruments used throughout the healthcare system where the opportunity for patient participation is likely and where it can have an important impact on healthcare delivery and patient outcomes.

We identified many instruments that indicate that participation is an important area of interest for healthcare researchers, which was also shown by the wide international scope and range of contexts for which the instruments were developed. Given that it is a new field, it is not surprising that there are many development parallels, which could even be seen as a strength, as the combined components of this research help build a coherent construct theory. However, the large number of instruments raises questions about the clinical relevance of the vast number of instruments measuring similar domains. Many of these instruments were developed and tested for specific diagnoses or contexts but could very well be used in other areas. The instrument questions were often general and concerned with access to information or the opportunity for patients to share in decision making about their care and treatment. There seems to be a lack of knowledge transfer and agreement 
on how to best measure patient participation and researchers have continued to modify the existing instruments rather than developing new instruments that are suitable for the current healthcare context-for example, those suitable for considering the individual in his or her environment and as a part of society. Thus, in future research, the large content overlap could be used to guide a unified patient participation measurement scale.

The findings in this review confirm the lack of environmental focus among researchers and thus, the insufficient knowledge transfer to healthcare professionals and policymakers on how to embed contextual factors in patient participation and the inherent decisionmaking processes [87]. That is, despite the consensus that the environment plays a vital role in supporting patients, especially those with complex health conditions, to overcome their limitations following illness, there was no single item considering the physical environment in the instruments included in this review. We are not the first to highlight that the environment is important to consider in patient participation and person-centered care. As Kvæl and Bergland [88] concluded in their study on the environment's influence on patient participation in the context of intermediate care of older people, the environment is not as recognized as it should be, even though it is a vital part of healthcare practice that mediates patient participation and supports person-centered care.

We do not mean that all instruments, in all healthcare settings, should address the physical and/or social environment. The purpose of this review was to scope the field to see if any instrument entailed such aspects. We argue that for healthcare staff working in home and community settings, as well as those involved in prehospital discharge planning sessions, having a dialogue with patients that includes the environment is crucial. However, no such instrument seems to exist, which may inspire future research. This is important, as today the home environment is the main place for care and rehabilitation $[23,33]$ and many decisions around the environment must be made. The home is very different from a hospital environment and can have physical (e.g., no elevator) and social (e.g., crowdedness, maintaining family life) characteristics that may be experienced as disabling. When a patient has complex care needs and is rehabilitated at home, the decision-making process cannot be simplified to consideration of a few alternatives. Their needs will change over time and the results may be affected by the environment, care provider, and context. As such, providers need to pay attention to and get involved in an iterative decision-making process that focuses also on daily life and considers the person's physical and social environment. Earlier studies have shown that this is not the norm in clinical practice today [27]. In this review, we found one instrument by Masters and colleagues [67] that could serve as inspiration for future development of instruments in transitional as well as home and community care. Knowledge about patients' experiences is key to improving care processes and their instrument contained a range of social-environmental aspects which measured the quality of care.

The generic instruments in this review had only a few items and focused on different facets of shared decision making, but mainly focused on patients' overall satisfaction with their care and the information provided. This finding is not surprising, as the focus traditionally has been on evaluating patients' experiences with participation in care decisions. Thus, the current assessments of shared decision making imply a very limited perspective of person-centered care, where, in addition to the experience of patient participation in care decisions, other aspects must be included. Moreover, some instruments focused on a meeting with a single healthcare professional-e.g., a meeting between a medical doctor and a patient, which limited their use. Today, healthcare is increasingly delivered by multidisciplinary healthcare teams; therefore, future patient participation instruments would benefit from not being tied to a specific profession.

The scoping review method in this work was useful, as the topic was both complex and heterogeneous in nature and provided us with an overview of the available instruments for measuring patient participation across the continuum of care $[8,14,89]$. The scope was broader than those of previous overviews aiming to evaluate instrument reliability and validity (e.g., see $[90,91])$. One strength of this review was that it was conducted by 
researchers with different professional backgrounds (nursing, social work, neurology, rehabilitation medicine, and occupational therapy), all with experience working with patients in partnerships. Thus, based on the clinical experiences of working with patients with complex health needs across a continuum of care, we argued that for patient participation instruments to be relevant and usable, they should include aspects of the physical and social environments.

\section{Limitations}

This review has some limitations that must be considered in the interpretation of the results. We searched a limited selection of databases, and although we identified a large number of studies and instruments, we might have missed some relevant instruments. In addition, we did not include an analysis of how much the instruments have been used, as this was beyond the scope. There might be instruments that were included that reached only the development phase. We did not assess the psychometric properties of the included instruments which could be helpful for potential users. However, unlike a systematic review, the purpose of a scoping review is to give an overview of a potentially large and diverse body of relevant literature [37]. In such an overview, a wide range of research designs could be included, and the material might not necessarily be quality appraised. In addition, the inconsistency with which participation, as a concept, was presented across instruments meant that we were unable to synthesize the material in a qualified way; thus, this synthesis should be prioritized in future research.

\section{Conclusions}

This review shows that there are a large number of instruments that measure participation, but few that include the environment as an important factor in decision making concerning care and treatment. Our work is the first to study instruments from this perspective and shows the current research gap in this area, thus demonstrating the need for further research.

Supplementary Materials: The following are available online at https://www.mdpi.com/article/10.3 390/ijerph19042003/s1, Figure S1: Shows the tailored search query of each database and follow-up search of the databases.

Author Contributions: Conceptualization, M.K., M.E. and U.-K.S.; methodology, M.K., M.E., U.-K.S. and H.P.-R.; validation, M.K., M.E., U.-K.S. and H.P.-R.; formal analysis, M.K., M.E. and U.-K.S.; writing—original draft preparation, M.K.; writing—review and editing, M.K., M.E., U.-K.S. and H.P.-R. All authors have read and agreed to the published version of the manuscript.

Funding: This work was supported by Dalarna University (grant number, N/A).

Institutional Review Board Statement: Not applicable.

Informed Consent Statement: Not applicable.

Data Availability Statement: All data relevant to the study are included in the article or uploaded as Supplemental Information.

Acknowledgments: We wish to thank Matthias Bank, a research support librarian at Lund University, for his help with the initial search.

Conflicts of Interest: The authors declare no conflict of interest.

\section{References}

1. Baker, A. Crossing the quality chasm: A new health system for the 21st century. BMJ 2001, 323, 1192. [CrossRef]

2. Morgan, S.; Yoder, L.H. A concept analysis of person-centered care. J. Holist. Nurs. 2012, 30, 6-15. [CrossRef]

3. Groene, O.; Garcia-Barbero, M. Health Promotion in Hospitals: Evidence and Quality Management; WHO Regional Office for Europe: Copenhagen, Denmark, 2005. Available online: http:/ / citeseerx.ist.psu.edu/viewdoc/download?doi=10.1.1.514.3778\&rep=rep1 \&type $=$ pdf (accessed on 15 December 2021). 
4. $\quad$ Phelan, A.; McCormack, B.; Dewing, J.; Brown, D.; Cardiff, S.; Cook, N.F.; Dickson, C.A.; Kmetec, S.; Lorber, M.; Magowan, R.; et al. Review of developments in person-centred healthcare. IPDJ 2020, 10. [CrossRef]

5. Shay, L.A.; Lafata, J.E. Where is the evidence? A systematic review of shared decision making and patient outcomes. Med. Decis. Mak. 2015, 35, 114-131. [CrossRef] [PubMed]

6. Meterko, M.; Wright, S.; Lin, H.; Lowy, E.; Cleary, P.D. Mortality among patients with acute myocardial infarction: The influences of patient-centered care and evidence-based medicine. Health Serv. Res. 2010, 45, 1188-1204. [CrossRef]

7. Veroff, D.; Marr, A.; Wennberg, D.E. Enhanced support for shared decision making reduced costs of care for patients with preference-sensitive conditions. Health Aff. 2013, 32, 285-293. [CrossRef] [PubMed]

8. Sahlsten, M.J.; Larsson, I.E.; Sjöström, B.; PLoS, K.A. An analysis of the concept of patient participation. In Nursing Forum; Wiley Online Library: Hoboken, NJ, USA, 2008; Volume 43, pp. 2-11.

9. World Health Organization. A Declaration on the Promotion of Patients' Rights in Europe; Regional Office for Europe: Copenhagen, Denmark, 1994. Available online: http://www.who.int/genomics/public/eu_declaration1994.pdf (accessed on 15 December 2021).

10. Longtin, Y.; Sax, H.; Leape, L.L.; Sheridan, S.E.; Donaldson, L.; Pittet, D. Patient participation: Current knowledge and applicability to patient safety. In Mayo Clinic Proceedings, 85; Elsevier: Amsterdam, The Netherlands, 2010; pp. 53-62. [CrossRef]

11. Coulter, A.; Ellins, J. Patient-Focused Interventions: A Review of the Evidence; Health Foundation: London, UK, 2006.

12. Larsson, B.W.; Larsson, G. Development of a short form of the Quality from the Patient's Perspective (QPP) questionnaire. J. Clin. Nurs. 2002, 11, 681-687. [CrossRef]

13. Jangland, E.; Gunningberg, L. Improving patient participation in a challenging context: A 2-year evaluation study of an implementation project. J. Nurs. Manag. 2017, 25, 266-275. [CrossRef]

14. Halabi, I.O.; Scholtes, B.; Voz, B.; Gillain, N.; Durieux, N.; Odero, A.; Baumann, M.; Ziegler, O.; Gagnayre, R.; Guillaume, M. Patient participation and related concepts: A scoping review on their dimensional composition. Patient. Educ. Couns. 2020, 103, 5-14. [CrossRef]

15. McCormack, B.; McCance, T.V. Development of a framework for person-centred nursing. J. Adv. Nurs. 2006, 56, 472-479. [CrossRef]

16. World Health Organization. International Classification of Functioning, Disability and Health; World Health Organization: Geneva, Switzerland, 2001.

17. Taylor, R. Kielhofner's Model of Human Occupation: Theory and Application, 5th ed.; Wolters Kluwer: Philadelphia, PA, USA, 2017.

18. Marcheschi, E.; Von Koch, L.; Pessah-Rasmussen, H.; Elf, M. Home setting after stroke, facilitators and barriers: A systematic literature review. Health Soc. Care Community 2018, 26, 451-459. [CrossRef]

19. Whiteneck, G.; Dijkers, M.P. Difficult to measure constructs: Conceptual and methodological issues concerning participation and environmental factors. Arch. Phys. Med. Rehabil. 2009, 90, 22-35. [CrossRef]

20. Stark, S. Creating disability in the home: The role of environmental barriers in the United States. Disabil. Soc. 2001, 16, 37-49. [CrossRef]

21. Hammel, J.; Magasi, S.; Heinemann, A.; Gray, D.B.; Stark, S.; Kisala, P.; Carlozzi, N.E.; Tulsky, D.; Garcia, S.F.; Hahn, E.A. Environmental barriers and supports to everyday participation: A qualitative insider perspective from people with disabilities. Arch. Phys. Med. Rehabil. 2015, 96, 578-588. [CrossRef]

22. Hestevik, C.H.; Molin, M.; Debesay, J.; Bergland, A.; Bye, A. Older persons' experiences of adapting to daily life at home after hospital discharge: A qualitative metasummary. BMC Health Serv. Res. 2019, 19, 224. [CrossRef] [PubMed]

23. SOU 2020:19. God och Nära Vård-En Reform för ett Hållbart Hälso-Och Sjukvårdssystem. Available online: https://www. vardanalys.se/om-vardanalys / remissyttranden/god-och-nara-vard-en-reform-for-ett-hallbart-halso-och-sjukvardssystem/ (accessed on 15 December 2021).

24. Goodwin, N.; Stein, V.; Amelung, V. What is integrated care? In Handbook Integrated Care; Springer: Cham, Switzerland, 2021; pp. 3-25.

25. Eccles, J.S.; Midgley, C.; Wigfield, A.; Buchanan, C.M.; Reuman, D.; Flanagan, C.; Mac Iver, D. Development during adolescence: The impact of stage-environment fit on young adolescents' experiences in schools and in families (1993). In The Evolution of Psychology: Fifty Years of the American Psychologist; Notterman, J.M., Ed.; American Psychological Association: Washington, DC, USA, 1997; pp. 475-501. [CrossRef]

26. Lawton, M.P.; Nahemow, L. Ecology and the aging process. In The Psychology of Adult Development and Aging; Eisdorfer, C., Lawton, M.P., Eds.; American Psychological Association: Washington, DC, USA, 1973.

27. Kylén, M.; Ytterberg, C.; von Koch, L.; Elf, M. How is the environment integrated into post-stroke rehabilitation? A qualitative study among community-dwelling persons with stroke who receive home rehabilitation in Sweden. Health Soc. Care Community 2021, 1-11. [CrossRef] [PubMed]

28. Langhorne, P.; Baylan, S. ESD Trialists. Early supported discharge services for people with acute stroke. Cochrane Database Syst. Rev. 2017. [CrossRef] [PubMed]

29. Lawrence, M.; Kinn, S. Defining and measuring patient-centred care: An example from a mixed-methods systematic review of the stroke literature. Health Expect. 2012, 15, 295-326. [CrossRef] [PubMed]

30. Zingmark, M.; Evertsson, B.; Haak, M. The content of reablement: Exploring occupational and physiotherapy interventions. Br. J. Occup. Ther. 2019, 82, 122-126. [CrossRef] 
31. Doh, D.; Smith, R.; Gevers, P. Reviewing the reablement approach to caring for older people. Ageing Soc. 2020, 40, 1371-1383. [CrossRef]

32. Castro, E.M.; Van Regenmortel, T.; Vanhaecht, K.; Sermeus, W.; Van Hecke, A. Patient empowerment, patient participation and patient-centeredness in hospital care: A concept analysis based on a literature review. Patient Educ. Couns. 2016, 99, 1923-1939. [CrossRef] [PubMed]

33. Bloem, B.R.; Henderson, E.J.; Dorsey, E.R.; Okun, M.S.; Okubadejo, N.; Chan, P.; Andrejack, J.; Darweesh, S.K.; Munneke, M. Integrated and patient-centred management of Parkinson's disease: A network model for reshaping chronic neurological care. Lancet Neurol. 2020, 19, 623-634. [CrossRef]

34. Almeida, R.S.; Bourliataux-Lajoinie, S.; Martins, M. Satisfaction measurement instruments for healthcare service users: A systematic review. Cad. Saude Publica 2015, 31, 11-25. [CrossRef] [PubMed]

35. Clayman, M.L.; Bylund, C.L.; Chewning, B.; Makoul, G. The impact of patient participation in health decisions within medical encounters: A systematic review. Med. Decis. Mak. 2016, 36, 427-452. [CrossRef]

36. Mora, M.A.; Sparud-Lundin, C.; Moons, P.; Bratt, E.-L. Definitions, instruments and correlates of patient empowerment: A descriptive review. Patient Educ. Couns. 2021, 105, 346-355. [CrossRef]

37. Arksey, H.; O’Malley, L. Scoping studies: Towards a methodological framework. Int. J. Soc. Res. Methodol. 2005, 8, 19-32. [CrossRef]

38. Levac, D.; Colquhoun, H.; O'Brien, K.K. Scoping studies: Advancing the methodology. Implement. Sci. 2010, 5, 69. [CrossRef]

39. Tricco, A.C.; Lillie, E.; Zarin, W.; O’Brien, K.K.; Colquhoun, H.; Levac, D.; Moher, D.; Peters, M.D.; Horsley, T.; Weeks, L. PRISMA extension for scoping reviews (PRISMA-ScR): Checklist and explanation. Ann. Intern. Med. 2018, 169, 467-473. [CrossRef]

40. Hupe, M. EndNote X9. J. Electron. Resour. Med. Libr. 2019, 16, 117-119. [CrossRef]

41. Ouzzani, M.; Hammady, H.; Fedorowicz, Z.; Elmagarmid, A. Rayyan-A web and mobile app for systematic reviews. Syst. Rev. 2016, 5, 210. [CrossRef]

42. Slade, M.; Jordan, H.; Clarke, E.; Williams, P.; Kaliniecka, H.; Arnold, K.; Fiorillo, A.; Giacco, D.; Luciano, M.; Égerházi, A. The development and evaluation of a five-language multi-perspective standardised measure: Clinical decision-making involvement and satisfaction (CDIS). BMC Health Serv. Res. 2014, 14, 323. [CrossRef] [PubMed]

43. Elwyn, G.; Barr, P.J.; Grande, S.W.; Thompson, R.; Walsh, T.; Ozanne, E.M. Developing CollaboRATE: A fast and frugal patientreported measure of shared decision making in clinical encounters. Patient Educ. Couns. 2013, 93, 102-107. [CrossRef] [PubMed]

44. Edwards, A.; Elwyn, G.; Hood, K.; Robling, M.; Atwell, C.; Holmes-Rovner, M.; Kinnersley, P.; Houston, H.; Russell, I. The development of COMRADE-A patient-based outcome measure to evaluate the effectiveness of risk communication and treatment decision making in consultations. Patient Educ. Couns. 2003, 50, 311-322. [CrossRef]

45. Brehaut, J.C.; O'Connor, A.M.; Wood, T.J.; Hack, T.F.; Siminoff, L.; Gordon, E.; Feldman-Stewart, D. Validation of a decision regret scale. Med. Decis. Mak. 2003, 23, 281-292. [CrossRef]

46. O'Connor, A.M. Validation of a Decisional Conflict Scale. Med. Decis. Mak. 1995, 15, 23-30. [CrossRef]

47. Aghili, R.; Khamseh, M.; Malek, M.; Banikarimi, A.; Baradaran, H.; Ebrahim Valojerdi, A. Development and validation of diabetes empowerment questionnaire in Iranian people with type 2 diabetes. Int. Nurs. Rev. 2013, 60, 267-273. [CrossRef]

48. Coluccia, A.; Ferretti, F.; Pozza, A. Health Services Outpatient Experience questionnaire: Factorial validity and reliability of a patient-centered outcome measure for outpatient settings in Italy. Patient. Relat. Outcome Meas. 2014, 5, 93-103. [CrossRef]

49. Mira, J.J.; Nuno-Solinis, R.; Guilabert-Mora, M.; Solas-Gaspar, O.; Fernandez-Cano, P.; Gonzalez-Mestre, M.A.; Contel, J.C.; Del Rio-Camara, M. Development and Validation of an Instrument for Assessing Patient Experience of Chronic Illness Care. Int. J. Integr. Care 2016, 16, 13. [CrossRef]

50. Wang, B.H.; Zhang, J.J.; Zhu, Q.; Zhang, J.; Yan, Q.Y. The Development and Psychometric Testing of Inpatient Involvement in Medication Safety Scale (IIMSS). J. Nurs. Manag. 2019, 28, 1648-1654. [CrossRef]

51. He, P.P.; Shen, Q.Q.; Chen, Y.S.; Yu, J.; Li, Z.X.; Ouyang, X.P. Development and validation of a Chinese-language instrument measuring empowerment needs of patients after a percutaneous coronary intervention. Nurs. Health Sci. 2020, 22, 364-373. [CrossRef]

52. Bomhof-Roordink, H.; Gärtner, F.R.; van Duijn-Bakker, N.; Van der Weijden, T.; Stiggelbout, A.M.; Pieterse, A.H. Measuring shared decision making in oncology: Development and first testing of the iSHAREpatient and iSHAREphysician questionnaires. Health Expect. 2020, 23, 496-508. [CrossRef] [PubMed]

53. Ilan, S.; Carmel, S. Patient communication pattern scale: Psychometric characteristics. Health Expect. 2016, 19, 842-853. [CrossRef] [PubMed]

54. Small, N.; Bower, P.; Chew-Graham, C.A.; Whalley, D.; Protheroe, J. Patient empowerment in long-term conditions: Development and preliminary testing of a new measure. BMC Health Serv. Res. 2013, 13, 263. Available online: http:/ / www.biomedcentral. com/1472-6963/13/263 (accessed on 15 December 2021). [CrossRef] [PubMed]

55. Bulsara, C.; Styles, I. Development of a cancer related patient empowerment scale using the polytomous Rasch measurement model. Cancer Clin. Oncol. 2013, 2, 87-102. [CrossRef]

56. $\mathrm{Xu}, \mathrm{R} . H . ;$ Cheung, A.W.L.; Wong, E.L.Y. Development and validation of an instrument to measure patient engagement in Hong Kong Special Administrative Region, China. Patient Prefer. Adherence 2018, 12, 1667. [CrossRef]

57. El Miedany, Y.; El Gaafary, M.; Youssef, S.; El Aroussy, N. Meaningful patient engagement in inflammatory arthritis: Development of the Patient Motivation Questionnaire. Clin. Rheumatol. 2017, 1-9. [CrossRef] 
58. Heggland, L.H.; Ogaard, T.; Mikkelsen, A.; Hausken, K. Patient participation in surgical treatment decision making from the patients' perspective: Validation of an instrument. Nurs. Res. Pract. 2012, 2012, 939675. [CrossRef]

59. Lindberg, J.; Kreuter, M.; Person, L.O.; Taft, C. Patient Participation in Rehabilitation Questionnaire (PPRQ)-development and psychometric evaluation. Spinal. Cord. 2013, 51, 838-842. [CrossRef]

60. Berg, S.K.; Færch, J.; Cromhout, P.F.; Tewes, M.; Pedersen, P.U.; Rasmussen, T.B.; Missel, M.; Christensen, J.; Juel, K.; Christensen, A.V. Questionnaire measuring patient participation in health care: Scale development and psychometric evaluation. Eur. J. Cardiovasc. Nurs. 2020, 19, 600-608. [CrossRef]

61. Ryan, B.L.; Brown, J.B.; Tremblay, P.F.; Stewart, M. Measuring Patients' Perceptions of Health Care Encounters: Examining the Factor Structure of the Revised Patient Perception of Patient-Centeredness (PPPC-R) Questionnaire. J. Patient Cent. Res. Rev. 2019, 6, 192-202. [CrossRef]

62. Ramond-Roquin, A.; Stewart, M.; Ryan, B.L.; Richards, M.; Sussman, J.; Brown, J.B.; Bouhali, T.; Bestard-Denomme, L.; Fortin, M. The "Patient-centered coordination by a care team" questionnaire achieves satisfactory validity and reliability. J. Interprof. Care 2019, 33, 558-569. [CrossRef] [PubMed]

63. Mitchell, K.A.R.; Brassil, K.J.; Fujimoto, K.; Fellman, B.M.; Shay, L.A. Springer AE: Exploratory factor analysis of a patientcentered cancer care measure to support improved assessment of patients' experiences. Value Health 2020, 23, 351-361. [CrossRef] [PubMed]

64. Smith, M.Y.; Winkel, G.; Egert, J.; Diaz-Wionczek, M.; DuHamel, K.N. Patient-physician communication in the context of persistent pain: Validation of a modified version of the patients' perceived involvement in care scale. J. Pain Symptom Manag. 2006, 32, 71-81. [CrossRef] [PubMed]

65. Arnetz, J.E.; Höglund, A.T.; Arnetz, B.B.; Winblad, U. Development and evaluation of a questionnaire for measuring patient views of involvement in myocardial infarction care. Eur. J. Cardiovasc. Nurs. 2008, 7, 229-238. [CrossRef] [PubMed]

66. Frank, C.; Asp, M.; Fridlund, B.; Baigi, A. Questionnaire for patient participation in emergency departments: Development and psychometric testing. J. Adv. Nurs. 2011, 67, 643-651. [CrossRef]

67. Masters, S.; Giles, L.; Halbert, J.; Crotty, M. Development and testing of a questionnaire to measure older people's experience of the Transition Care Program in Australia. Australas. J. Ageing 2010, 29, 172-178. [CrossRef]

68. Simon, D.; Schorr, G.; Wirtz, M.; Vodermaier, A.; Caspari, C.; Neuner, B.; Spies, C.; Krones, T.; Keller, H.; Edwards, A. Development and first validation of the shared decision-making questionnaire (SDM-Q). Patient Educ. Couns. 2006, 63, 319-327. [CrossRef]

69. Légaré, F.; Kearing, S.; Clay, K.; Gagnon, S.; D'Amours, D.; Rousseau, M.; O'Connor, A. Are you SURE? Assessing patient decisional conflict with a 4-item screening test. Can. Fam. Physician 2010, 56, 308-314.

70. Kriston, L.; Scholl-Hölzel, L.; Simon, D.; Loh, A.; Härter, M. The 9-item Shared Decision Making Questionnaire (SDM-Q-9). Development and psychometric properties in a primary care sample. Patient Educ. Couns. 2010, 80, 94-99. [CrossRef]

71. Evensen, C.T.; Yost, K.J.; Keller, S.; Arora, N.K.; Frentzel, E.; Cowans, T.; Garfinkel, S.A. Development and Testing of the CAHPS Cancer Care Survey. J. Oncol. Pract. 2019, 15, 969-978. [CrossRef]

72. Eskildsen, N.B.; Ross, L.; Bulsara, C.; Dietz, S.M.; Thomsen, T.G.; Groenvold, M.; Pedersen, S.S.; Jørgensen, C.R.; Johnsen, A.T. Development and content validation of a questionnaire measuring patient empowerment in cancer follow-up. Qual. Life Res. 2020, 29, 2253-2274. [CrossRef] [PubMed]

73. Coleman, E.A.; Mahoney, E.; Parry, C. Assessing the quality of preparation for posthospital care from the patient's perspective: The care transitions measure. Med. Care 2005, 43, 246-255. Available online: http:/ / www.jstor.org/stable/3768223 (accessed on 15 December 2021). [CrossRef]

74. Berendsen, A.J.; Groenier, K.H.; de Jong, G.M.; Meyboom-de Jong, B.; van der Veen, W.J.; Dekker, J.; de Waal, M.W.; Schuling, J. Assessment of patient's experiences across the interface between primary and secondary care: Consumer Quality Index Continuum of care. Pat. Educ. Counsel. 2009, 77, 123-127. [CrossRef] [PubMed]

75. Degner, L.F.; Sloan, J.A.; Venkatesh, P. The Control Preferences Scale. Can. J. Nurs. Res. 1997, 29, 21-43. [PubMed]

76. Finnell, D.S.; Lee, J. Psychometric Properties of the Decisional Balance for Patient Choice in Substance Abuse Treatment. Issues Ment. Health Nurs. 2011, 32, 243-249. [CrossRef]

77. Hoerger, M.; Chapman, B.P.; Mohile, S.G.; Duberstein, P.R. Development and psychometric evaluation of the Decisional Engagement Scale (DES-10): A patient-reported psychosocial survey for quality cancer care. Psych. Assess 2016, 28, 1087-1100. [CrossRef]

78. Hibbard, J.H.; Stockard, J.; Mahoney, E.R.; Tusler, M. Development of the patient activation measure (PAM): Conceptualizing and measuring activation in patients and consumers. Health Serv. Res. 2004, 39, 1005-1026. [CrossRef]

79. Chaboyer, W.; Harbeck, E.; Bucknall, T.; McInnes, E.; Thalib, L.; Whitty, J.; Wallis, M.; Gillespie, B. Initial psychometric testing and validation of the patient participation in pressure injury prevention scale. JAN 2017, 73, 2237-2247. [CrossRef]

80. Singer, S.J.; Friedberg, M.W.; Kiang, M.V.; Dunn, T.; Kuhn, D.M. Development and preliminary validation of the Patient Perceptions of Integrated Care survey. Med. Care Res. Rev. 2013, 70, 143-164. [CrossRef]

81. Jerofke, T.; Weiss, M. Development and psychometric analysis of the Patient Perceptions of Patient-Empowering Nurse Behaviours Scale (PPPNBS). JAN 2016, 72, 2923-2936. [CrossRef]

82. Eldh, A.C.; Luhr, K.; Ehnfors, M. The development and initial validation of a clinical tool for patients' preferences on patient participation-The 4Ps. Health Expect. 2015, 18, 2522-2535. [CrossRef] [PubMed] 
83. Casu, G.; Gremigni, P.; Sommaruga, M. The Patient-Professional Interaction Questionnaire (PPIQ) to assess patient centered care from the patient's perspective. Patient Educ. Couns. 2019, 102, 126-133. [CrossRef] [PubMed]

84. Jenkinson, C.; Coulter, A.; Bruster, S. The Picker Patient Experience Questionnaire: Development and validation using data from in-patient surveys in five countries. Int. J. Qual. Health Care 2002, 14, 353-358. [CrossRef] [PubMed]

85. Bennett, C.; Graham, I.D.; Kristjansson, E.; Kearing, S.A.; Clay, K.F.; O'Connor, A.M. Validation of a preparation for decision making scale. Patient Educ. Couns. 2010, 78, 130-133. [CrossRef] [PubMed]

86. Tzelepis, F.; Sanson-Fisher, R.W.; Hall, A.E.; Carey, M.L.; Paul, C.L.; Clinton-McHarg, T. Development and psychometric evaluation of the Quality of Patient-Centered Cancer Care measure with hematological cancer survivors. Cancer 2015, 121, 2383-2392. [CrossRef]

87. Schneidert, M.; Hurst, R.; Miller, J.; Üstün, B. The role of environment in the International Classification of Functioning, Disability and Health (ICF). Disabil. Rehabil. 2003, 25, 588-595. [CrossRef]

88. Kvæl, L.A.H.; Bergland, A. The practice environment's influence on patient participation in intermediate healthcare services-The perspectives of patients, relatives and healthcare professionals. BMC Health Serv. Res. 2021, 21, 180. [CrossRef]

89. Fulop, N. (Ed.) Studying the Organisation and Delivery of Health Services: Research Methods; Routledge: London, UK, 2001.

90. Scholl, I.; Koelewijn-van Loon, M.; Sepucha, K.; Elwyn, G.; Légaré, F.; Härter, M.; Dirmaier, J. Measurement of shared decision making-A review of instruments. Z. Evid. Fortbild. Qual. Gesundhwes. 2011, 105, 313-324. [CrossRef] [PubMed]

91. Phillips, N.M.; Street, M.; Haesler, E. A systematic review of reliable and valid tools for the measurement of patient participation in healthcare. BMJ Qual. Saf. 2016, 25, 110-117. [CrossRef] 